\title{
Relação econômica dos setores agrícolas do Estado do Mato Grosso com os demais setores pertencentes tanto ao Estado quanto ao restante do Brasil
}

\author{
Margarida Garcia de Figueiredo* \\ Alexandre Lahós Mendonça de Barros** \\ Joaquim José Martins Guilhoto***
}

Resumo: Pesquisas atuais mostram que o setor agropecuário do Mato Grosso tem apresentado elevado desempenho nos últimos anos, ocupando posição de setor-chave no desenvolvimento econômico do Estado. Este trabalho visa mostrar de forma empírica a importância relativa do setor agrícola na estrutura produtiva do estado, utilizando-se de um modelo insumo-produto inter-regional construído para duas regiões, a saber, Mato Grosso e o restante do Brasil, referente ao ano de 1999. Procurouse identificar os setores mais importantes das economias em questão, seus encadeamentos e a propagação de impactos entre as regiões, além de avaliar qual o impacto das exportações de soja mato-grossenses sobre a produção total das demais atividades. Confirmou-se a hipótese formulada a respeito da importância dos setores primários para a economia do estado, verificando-se que alguns setores agrícolas e outros diretamente relacionados a estes foram identificados como chaves ou pólos de desenvolvimento econômico na região em estudo. Em especial, merece destaque a cultura da soja no Mato Grosso, a qual apresenta um elevado efeito multiplicador do emprego e renda, destacando-se também como pólo de desenvolvimento econômico, além da importância que têm as suas exportações para a economia, atraindo ganhos cambiais ao

\footnotetext{
*Aluna de Doutorado em Economia Aplicada da ESALQ/USP. mgfiguei@esalq.usp.br

**Professor Doutor na Fundação Getúlio Vargas, FGV-SP. almb@fgvsp.br

***Professor titular no Departamento de Economia, FEA - USP E. guilhoto@usp.br
} 
país e impactando positivamente na produção de diversos outros setores. Finalmente, o trabalho desenvolve um ferramental útil para a formulação de políticas públicas para o Estado do Mato Grosso.

Palavras-chave: agricultura, insumo-produto e desenvolvimento econômico.

\section{Classificação JEL: D57}

Abstract: The purpose of this paper is to empirically show the relative importance of the agricultural sector in the productive framework of Mato Grosso State (Brazil), an inter-regional input-output model for two regions: Mato Grosso and the rest of Brazil for 1999.

The idea was to identify the most important sectors of the economies in question, their connections and the propagation of impacts between regions, besides verifying the impact on the Mato Grosso soybean exports on the total production of other activities. The hypothesis on the importance of the primary sectors for the state economy has been confirmed, and some agricultural sectors and others directly linked thereto have been found to be key-sectors, or centers of economic growth in the region under study. Special mention should be given to soybean culture in Mato Grosso State, which shows a high employment and income multiplying effect on the economy, as well as being a center of economic growth and major exporter, attracting exchange gains to the country and positively impacting the production of other sectors. Finally, this paper provides a useful tool for drafting public policies for Mato Grosso State.

Key-words: agriculture, input-output and economic development.

JEL Classification: D57 Input-Output Analysis

\section{Introdução}

A importância da agricultura para o crescimento de um país sempre foi um tópico de grande relevância dentro da teoria econômica. Os 
estudiosos clássicos do tema, por exemplo, já investigavam os diversos papéis a serem desempenhados pela agricultura no processo de desenvolvimento econômico, constituindo tópico relevante para economias em transição, como é o caso do Brasil.

Moura et al. (1999) realizaram estudos indicando que o setor agrícola pode gerar um efeito benéfico para o resto da economia ao ser estimulado, ou seja, emana efeitos indutores positivos para os demais setores. Além disto mostraram que, ao priorizar as atividades no setor como “mola propulsora” do crescimento econômico, um país estará fazendo uma opção por um grau mais elevado de eficiência na alocação de seus recursos, principalmente no caso daquele que ainda não atingiu os padrões de desenvolvimento considerados satisfatórios.

Nos países em desenvolvimento, como o Brasil, a importância do setor agrícola é bastante significativa, conforme se espera. Em 2001, o PIB do setor agropecuário brasileiro de R \$99,40 bilhões - segundo dados da Confederação Nacional da Agricultura e Pecuária, em parceria com o Centro de Estudos Avançados em Economia Aplicada da Universidade de São Paulo (CNA/CEPEA-USP, 2003) - contribuiu com cerca de $8 \%$ na formação do PIB nacional, que de acordo com dados das Contas Nacionais, divulgadas pelo Instituto Brasileiro de Geografia e Estatística (IBGE, 2003), chegou a R\$1.200,06 bilhões em preços correntes de 2001. Além disto, o PIB do agronegócio brasileiro, que inclui desde a produção primária até a indústria de processamento, insumos e serviços, atingiu $\mathrm{R} \$$ 344,95 bilhões em 2001, representando cerca de $28 \%$ do PIB nacional.

Responsável por cerca de $27 \%$ da oferta global de soja ${ }^{1}$, de acordo com estatísticas da Food and Agriculture Organization of the United Nations (FAO, 2003), o Brasil ocupa atualmente, a posição de segundo maior produtor mundial do grão, perdendo apenas para os Estados Unidos, mas na frente de países como Argentina e China.

A expansão da cultura contribuiu para uma série de mudanças na história do país, tendo sido, em parte, responsável pela aceleração da mecanização das lavouras, pela modernização do sistema de transportes, pela expansão da fronteira agrícola, pela profissionalização e incremento do comércio

\footnotetext{
${ }^{1}$ A produção nacional de soja, em 2003, somou 51,53 milhões de toneladas, segundo estatísticas da FAO.
} 
internacional, dentre outras contribuições, conforme destacado em estudo da Empresa Brasileira de Pesquisa Agropecuária (EMBRAPA, 2002).

Deve-se destacar, ainda, a importância da soja no mercado externo, já que as vendas de seu complexo agroindustrial representam em torno de $24 \%$ das exportações do agronegócio brasileiro, respondendo por cerca de $10 \%$ das remessas totais ao exterior, segundo estatísticas da Companhia Nacional do Abastecimento (CONAB, 2003).

Merece destaque nesse cenário o Estado do Mato Grosso, tanto pelo notável desenvolvimento de suas atividades agrícolas na última década quanto por sua liderança nacional em termos de produção e produtividade de soja. Sua receita com a exportação do grão foi cerca de US $\$ 736$ milhões em 2002, respondendo por $24,3 \%$ da receita nacional, segundo estatísticas do Ministério do Desenvolvimento, Indústria e Comércio Exterior (MDIC, 2003).

O desenvolvimento da economia daquele estado está relacionado com a expansão da fronteira agrícola do Centro-Oeste, a partir das décadas de 1950 e 1960. Posteriormente, nos anos 70, a presença do Mato Grosso foi fundamental para a criação de projetos de desenvolvimento regional, como o Prodoeste, Polamazônia e Polocentro com incentivos fiscais e facilidade de crédito para a produção agrícola, conforme salientado por Oliveira (2003).

Outro fator que contribuiu para o desenvolvimento da agricultura no Centro-Oeste foi o preço baixo da terra. Entretanto, a ocupação do cerrado só foi possível devido aos avanços nas pesquisas desenvolvidas para tal região, que viabilizaram tecnicamente a produção da soja pelo uso de novas variedades adaptadas às condições edafoclimáticas e de latitude do cerrado (Sousa, 1990).

Dessa forma, a Região Centro-Oeste, em especial o Mato Grosso, foi se desenvolvendo em ritmo acelerado, representando, nos dias de hoje, o principal pólo de produção agrícola do Brasil. Isto torna interessante a realização de estudos que venham a averiguar a importância relativa do setor agrícola dentro da estrutura produtiva do referido estado.

Assim, o presente estudo procura quantificar as relações comerciais dos setores primários pertencentes ao Mato Grosso, tanto com os setores secundários e terciários pertencentes ao próprio estado, quanto com os pertencentes às demais regiões brasileiras. Procura, também, avaliar a importância dos setores primários no que diz respeito às suas capacidades 
de geração de emprego e renda na economia.

Finalmente, verifica se as características analisadas, de fato, conferem aos setores agrícolas da economia mato-grossense alguns dos papéis atribuídos à agricultura no processo de desenvolvimento econômico, conforme enumerado pelo trabalho clássico de Johnston e Mellor (1961).

Vale ressaltar que os setores pertencentes ao restante do Brasil foram utilizados no sentido de verificar a influência dos setores mato-grossenses sobre os mesmos e a análise específica para cada indicador não faz parte dos objetivos principais deste artigo.

\section{Metodologia}

\subsection{Fonte de dados}

Utilizou-se como fonte de dados a matriz insumo-produto inter-regional para o Mato Grosso e restante do Brasil, em 51 setores, referente ao ano de 1999. Ela foi estimada a partir da matriz inter-regional dos Estados da Amazônia Legal e restante do Brasil (em 90 setores), desenvolvida pela equipe "Projeções Econômicas", coordenada pelo professor Joaquim José Martins Guilhoto. Esta matriz para os estados da Amazônia Legal foi obtida a partir da matriz nacional (em 90 setores) para 1999, desagregada da matriz nacional (em 42 setores) para o mesmo ano, que por sua vez foi estimada a partir dos dados preliminares das Contas Nacionais para 1999, de acordo com metodologia desenvolvida por Guilhoto et al. (2002)a.

Uma vez obtida, a matriz inter-regional Mato Grosso x Restante do Brasil foi agregada para 51 setores, de modo que, para atender os objetivos específicos do estudo, não há necessidade em se trabalhar com 90 setores produtivos. O critério utilizado foi o de seguir a classificação oficial do IBGE (de 42 setores), porém agregando alguns de pouca relevância tanto para a economia do estado quanto para os interesses da pesquisa, e desagregando outros diretamente relacionados à agropecuária, por exemplo, o setor da soja e o de bovinos.

Partindo dos coeficientes da matriz inversa de Leontief, calculou-se a capacidade de geração de emprego e renda para cada setor, bem como os índices de ligações Hirschman-Rasmussen e os índices puros de ligações, 
identificando-se os setores considerados como pólos de desenvolvimento econômico, de modo a caracterizar a estrutura produtiva do Mato Grosso, inclusive relacionando-a com a economia do restante do país. Além disto, calculou-se o valor da produção gerado na economia ao atender às exportações de soja do Mato Grosso.

\subsection{Modelo teórico}

Os modelos insumo-produto, desenvolvidos por Wassily Leontief em 1930, em sua concepção teórico-empírica colocam a análise dos grandes agregados macroeconômicos em termos de relações de insumos e produtos, estabelecendo um quadro em que a economia é descrita em termos de circulação, isto é, como um sistema integrado de fluxos e transferências de insumos e produtos de um setor a outro, no qual todos os produtos, de acordo com seu destino, podem ser insumos na medida em que sejam aproveitáveis por outro sistema em cadeia.

Embora o Modelo Insumo-Produto de Wassily Leontief seja originariamente elaborado para estudos das relações internas da economia de uma nação, o recente interesse pela análise econômica em âmbito regional tem induzido modificações nos modelos visando adaptá-los às investigações de determinadas regiões e suas relações com as demais. Inúmeros exemplos de modelos e aplicações de insumo-produto para estudos regionais podem ser identificados, desde os voltados somente para uma região como aqueles destinados a várias regiões, países ou mesmo para blocos internacionais.

Alguns estudos regionais que fizeram uso de modelos de insumoproduto referem-se aos trabalhos de Guilhoto (1999), Guilhoto et al. (2002)b, Montoya (1998), Crocomo (1998), Silveira (2000), Parré (2000), Moretto (2000), Silva (2001), Isard (1998).

Especificamente neste estudo, utilizou-se um modelo inter-regional desenvolvido para duas regiões, cujo modelo teórico encontra-se descrito a seguir.

Os fluxos inter-setoriais em uma economia podem ser representados por:

$$
X=A X+Y
$$


No qual X é um vetor (nx1) com os valores da produção total de cada setor, Y é um vetor (nx1) com os valores da demanda final, e A é uma matriz (nxn) com os coeficientes técnicos de produção (Leontief, 1966). Neste modelo, o vetor da demanda final pode ser considerado como exógeno ao sistema, então o nível total de produção pode ser determinado pela demanda final, da seguinte forma:

$$
\begin{aligned}
& X=B Y \\
& B=(I-A)^{-1}
\end{aligned}
$$

Sendo B uma matriz (nxn) Inversa de Leontief.

Pela equação (2) é possível estimar o impacto da demanda final na produção total e, a partir daí, no emprego e salário.

Os indicadores econômicos calculados para a análise da estrutura produtiva da economia foram os Índices de Rasmussen-Hirschman, os Índices Puros de Ligações, e os Multiplicadores de Emprego e Renda. Foram realizados Choques de demanda final, os quais permitiram avaliar o impacto das exportações de soja do Mato Grosso sobre a produção de toda a economia.

\section{Índices de Rasmussen-Hirschman}

Para o cálculo desses índices define-se $b_{j}$ como sendo um elemento da matriz inversa de Leontief $\mathbf{B}$; $\mathbf{B}^{*}$ como sendo a média de todos os elementos de $\mathbf{B}$ e $\mathbf{B}_{* j}, B_{i *}$ como sendo, respectivamente, a soma de uma coluna e de uma linha típica de $\boldsymbol{B}$.

$$
U_{j}=\left[B *_{j} / n\right] / B^{*}
$$

define os índices de ligações para trás (poder de dispersão)

e

$$
U_{j}=\left[B_{i^{*}} / n\right] / B^{*}
$$

define os índices de ligações para frente (sensibilidade da dispersão)

\section{Índices Puros de Ligações}

Baseado em Guilhoto et al. (1996), o cálculo dos índices puros de ligações parte da decomposição de uma matriz A, que contém os coeficientes de insumos diretos do setor destacado j e o resto da economia: 


$$
A=\left[\begin{array}{cc}
A_{j j} & A_{j r} \\
A_{r j} & A_{r r}
\end{array}\right]=\left[\begin{array}{cc}
A_{j j} & A_{j r} \\
A_{r j} & 0
\end{array}\right]+\left[\begin{array}{cc}
0 & 0 \\
0 & A_{r r}
\end{array}\right]=A_{j}+A_{r}
$$

No qual $A_{j j}$ e $A_{r r}$ são, respectivamente, matrizes que representam insumos diretos do setor j e do resto da economia; $A_{r j}$ e $A_{j r}$ representam matrizes dos insumos diretos comprados pelo setor $\mathbf{j}$ do resto da economia e os insumos diretos comprados pelo resto da economia do setor $\mathbf{j}$. A matriz $A_{j}$ representa o setor $\mathbf{j}$ isolado do resto da economia e a matriz $A_{r}$ representa o resto da economia.

Partindo da equação acima chega-se a:

$B=(I-A)^{-1}=\left[\begin{array}{cc}B_{j j} & B_{j r} \\ B_{r j} & B_{r r}\end{array}\right]=\left[\begin{array}{cc}\Delta_{j j} & 0 \\ 0 & \Delta_{r r}\end{array}\right]\left[\begin{array}{cc}\Delta_{j} & 0 \\ 0 & \Delta_{r}\end{array}\right]\left[\begin{array}{cc}I & A_{j r} \Delta_{r} \\ A_{r j} \Delta_{j} & I\end{array}\right]$

sendo

$$
\begin{aligned}
\Delta_{j} & =\left(I-A_{j j}\right)^{-1} \\
\Delta_{r} & =\left(I-A_{r r}\right)^{-1} \\
\Delta_{j j} & =\left(I-\Delta_{j} A_{j r} \Delta_{r} A_{r j}\right)^{-1} \\
\Delta_{r r} & =\left(I-\Delta_{r} A_{r j} \Delta_{j} A_{j r}\right)^{-1}
\end{aligned}
$$

As novas definições para os índices de ligações para trás e para frente serão dadas por:

$$
\begin{aligned}
& P B L=\Delta_{r} A_{r j} \Delta_{j} Y_{j} \\
& P F L=\Delta_{j} A_{j r} \Delta_{r} Y_{r}
\end{aligned}
$$

o PBL indicará o impacto puro sobre o resto da economia do valor da produção total na região $j$. Impacto puro porque, segundo Guilhoto et al. (1996), ele está livre: (a) da demanda de insumos que a região $j$ produz para a região $j$; (b) dos retornos do resto da economia para a região $j$ e vice versa. Por sua vez, o $P F L$ indicará o impacto puro sobre a região $j$, do valor da produção total no resto da economia $r$. 
O índice puro total de ligações (PTL) de cada setor na economia é obtido adicionando-se o PBL ao PFL, visto que estes índices são expressos em valores correntes.

$$
\mathrm{PTL}=\mathrm{PBL}+\mathrm{PFL}
$$

\section{Multiplicadores de emprego}

O multiplicador de emprego para um determinado setor j é dado por:

$$
M E_{j}=\sum_{i=1}^{n}\left(w_{n+1, i} b_{i j}\right) / w_{n+1, j}
$$

No qual:

$\mathbf{W}_{\mathfrak{n}+1}$ é o número de empregos gerados por unidade monetária produzida

$b_{i j}$ representa os elementos da Inversa de Leontief.

\section{Multiplicadores de renda}

Algebricamente, tem-se o multiplicador:

$$
M R_{j}=\sum_{i=1}^{n}\left(a_{n+1, i} b_{i j}\right) / a_{n+1, j}
$$

Sendo:

$a_{n+1, i}$ corresponde aos elementos da linha dos coeficientes de remuneração das famílias

$b_{i j}$ representa os elementos da inversa de Leontief.

\section{Choques de demanda final}

Os choques de demanda final são calculados a partir da multiplicação da matriz Inversa de Leontief pelo vetor cujo impacto se pretende analisar, que no caso específico deste trabalho são as exportações de soja do Estado do Mato Grosso.

$$
\mathrm{X}=\mathrm{L} * \text { Expsoja }
$$

Sendo,

$X=$ produção gerada na economia como um todo para atender as exportações de soja do Mato Grosso 
$I L=$ Matriz Inversa de Leontief

Expsoja = Exportações de soja do Mato Grosso

Vale notar que podem ser feitas simulações de variações nas exportações alterando-se os valores do vetor na proporção que se deseja analisar e multiplicando-se novamente pela matriz Inversa de Leontief para comparação dos resultados.

\section{Resultados e Discussão²}

\section{1 Índices de ligações intersetoriais}

Os índices de Rasmussen-Hirschman e os índices puros de ligações normalizados foram calculados para a identificação dos setores-chave ou pólos de desenvolvimento do estado. Os valores apresentados são relativos à média da economia e aqueles maiores do que 1 indicam que o nível de encadeamento do setor é superior à média dos demais e, portanto, estes representam setores-chave ao desenvolvimento econômico da região.

\subsection{1 Índices de Rasmussen-Hirschman}

Os resultados encontrados para os índices de Rasmussen-Hirschman encontram-se na Tabela 1. Os principais setores do Mato Grosso com fortes ligações para trás, os quais dinamizam a economia ao se destacarem como importantes compradores de bens e serviços das demais atividades, estão praticamente todos diretamente relacionados ao setor primário.

Nota-se que o principal setor mato-grossense com fortes ligações para trás é o Eletro-eletrônicos, uma atividade pouco expressiva para o estado; entretanto, como este índice não leva em consideração o valor da produção e o referido setor utiliza a produção de diversas atividades como insumo (plástico, metal, tinta etc), este acabou ocupando a primeira posição no ranking em termos de ligações para trás. Situação semelhante ocorreu nos setores Peças e veículos, Indústria do café, Fabricação de açúcar, dentre outros.

${ }^{2}$ Banco de dados original encontra-se em Figueiredo (2003), onde se encontram os valores dos indicadores para os 51 setores. 
A segunda posição no ranking ficou para o setor Abate de bovinos, a sexta para Fabricação de óleos vegetais, a sétima para Abate de outros animais, enfim, diversas atividades pertencentes ao agronegócio se destacaram, dinamizando a economia por constituírem o mercado consumidor dos demais setores.

Com relação aos principais setores com fortes ligações para frente, os quais dinamizam a economia ao se destacarem como importantes fornecedores de matéria-prima, quando não fazem parte do setor terciário, como é o caso do Comércio, dos Serviços Industriais de Utilidade Pública (S.I.U.P.), dos Serviços prestados às empresas, da Administração pública, dentre outros, também estão praticamente todos diretamente relacionados ao setor primário, como por exemplo, os setores da Canade-açúcar, Milho, Soja e Outras culturas.

Tabela 01. Índices de Hirschman-Rasmussen para o Mato Grosso.

\begin{tabular}{|l|c|c|c|c|}
\hline \multicolumn{1}{|c|}{ Setores } & Trás & Ordem & Frente & Ordem \\
\hline Cana-de-açúcar & 0,83 & 41 & 1,25 & 9 \\
\hline Soja & 0,84 & 39 & 1,08 & 15 \\
\hline Milho & 0,89 & 32 & 1,08 & 14 \\
\hline Outras culturas & 0,80 & 46 & 1,55 & 5 \\
\hline Bovinos & 0,81 & 44 & 1,19 & 12 \\
\hline Eletro-eletrônicos & 1,33 & 1 & 0,69 & 44 \\
\hline Peças e veículos & 1,31 & 3 & 0,68 & 48 \\
\hline Indústria do café & 1,29 & 4 & 0,74 & 40 \\
\hline Abate de outros animais & 1,25 & 7 & 0,76 & 36 \\
\hline Abate de bovinos & 1,33 & 2 & 0,76 & 37 \\
\hline Fabricação de açúcar & 1,22 & 9 & 0,91 & 21 \\
\hline Fabricação de óleos vegetais & 1,27 & 6 & 1,14 & 13 \\
\hline S.I.U.P & 1,12 & 16 & 1,90 & 2 \\
\hline Comércio & 0,97 & 26 & 3,04 & 1 \\
\hline Serviços prestados às empresas & 0,85 & 38 & 1,57 & 4 \\
\hline Administração pública & 0,81 & 45 & 1,50 & 6 \\
\hline
\end{tabular}

Fonte: Resultados da pesquisa.

Entretanto, apesar de os índices de Rasmussen-Hirschman serem amplamente utilizados na identificação de setores-chave, especialmente na análise da estrutura produtiva da economia, estes não levam em consideração o valor da produção total das indústrias, apontando apenas 
o grau de ligação de cada uma às demais, devendo-se, portanto, complementar sua análise por meio dos índices puros de ligações, os quais levam em consideração o valor da produção de cada setor.

\subsection{2 Índices puros de ligações normalizados}

A Tabela 2 apresenta os índices puros de ligações totais normalizados. Valores acima de um identificam os setores considerados como chave ou pólos de desenvolvimento econômico, ao se destacarem tanto por suas relações de compra quanto por suas relações de venda na economia, conforme exposto.

É interessante observar que, ao levar em consideração o valor da produção total de cada atividade, alguns setores primários (e outros diretamente relacionados a eles) ganham posição no ranking em termos da importância relativa de suas relações comercias na economia, como é o caso dos setores Fabricação de óleos vegetais, que passa a ocupar a terceira posição; Soja, ocupando a sétima posição; Bovinos, na oitava posição; Abate de bovinos, décima posição, e assim por diante.

O principal setor destacado por suas fortes relações comerciais foi o Comércio, com relações de compra e venda 10,2 vezes acima da média quando comparado às demais atividades, o que se justifica pelo fato de ser o canal de comercialização entre todos os setores.

Tabela 02. Índices puros de ligações totais normalizados para o Mato Grosso.

\begin{tabular}{|l|c|c|}
\hline \multicolumn{1}{|c|}{ Setores } & Total & Ordem \\
\hline Soja & 2,24 & 7 \\
\hline Bovinos & 2,22 & 8 \\
\hline Outros pecuária & 1,20 & 15 \\
\hline Eletro-eletrônicos & 0,00 & 50 \\
\hline Peças e veículos & 0,00 & 49 \\
\hline Abate de outros animais & 1,72 & 12 \\
\hline Abate de bovinos & 1,77 & 10 \\
\hline Fabricação de óleos vegetais & 3,08 & 3 \\
\hline Comércio & 10,20 & 1 \\
\hline Serviços prestados às empresas & 2,46 & 2 \\
\hline Administração pública & 4,51 & \\
\hline
\end{tabular}

Fonte: Resultados da pesquisa. 


\subsection{Geração de emprego na economia}

No que diz respeito à capacidade de geração de empregos na economia, verificou-se que, ao atender a demanda final do setor da soja no Mato Grosso em R\$ 1 milhão, são gerados 8 empregos diretamente na própria atividade, 31 indiretamente nas demais atividades e 72 quando considerado o efeito induzido pelo consumo das famílias endogeneizado no sistema, conforme exposto na Tabela 3.

Deve-se ressaltar que dentro dos empregos indiretos e induzidos estão incluídos tanto aqueles gerados no próprio estado, quanto os gerados no restante do país. A mesma relação é válida também para os demais setores. Nota-se, a partir do resultado acima apresentado, que a capacidade de geração direta de empregos pelo setor da soja é de fato modesta, pois se trata de um setor altamente mecanizado e relativamente intensivo em capital. Entretanto, observa-se que a produção apresenta, em contrapartida, elevada capacidade de multiplicar este emprego nas atividades fornecedoras de insumos à sua produção.

Tabela 03. Geração de empregos diretos, indiretos e induzidos para a variação de um milhão de Reais da demanda final pela produção do Mato Grosso.

\begin{tabular}{|l|c|c|c|}
\hline \multicolumn{1}{|c|}{ Setores } & Diretos & Indiretos & Induzidos \\
\hline Soja & 8 & 31 & 72 \\
\hline Bovinos & 51 & 56 & 78 \\
\hline Extrativismo vegetal & 160 & 31 & 83 \\
\hline Beneficiamento de produtos vegetais & 68 & 89 & 78 \\
\hline Abate de outros animais & 8 & 171 & 75 \\
\hline Abate de bovinos & 5 & 78 & 75 \\
\hline Fabricação de óleos vegetais & 1 & 39 & 69 \\
\hline Comércio & 28 & 21 & 81 \\
\hline Transporte rodoviário & 30 & 17 & 83 \\
\hline Transporte ferroviário & 23 & 16 & 93 \\
\hline Instituições financeiras & 10 & 16 & 105 \\
\hline Serviços privados não mercantis & 590 & 4 & 125 \\
\hline
\end{tabular}

Fonte: Resultados da pesquisa. 
Relação econômica dos setores agrícolas do Estado do Mato Grosso com os demais setores pertencentes tanto ao Estado quanto ao restante do Brasil

\subsection{Geração de renda na economia}

Com relação à capacidade de geração de renda (entenda-se salários), a Tabela 4 mostra que os setores Soja, Bovinos, Aves, Extrativismo vegetal, Abate de bovinos, Abate de outros animais, Fabricação de óleos vegetais e Adubos e fertilizantes, pertencentes ao Mato Grosso, geram um baixo nível de renda diretamente na própria atividade ao atenderem suas demandas finais em R 1 milhão. No entanto, têm elevado efeito multiplicador da renda na economia, gerando elevados níveis de rendas nas indústrias fornecedoras de insumos às suas produções, o que consiste em importante característica para a economia.

Tabela 04. Geração de renda direta, indireta e induzida para a variação de um milhão de Reais da demanda final pela produção do Mato Grosso.

\begin{tabular}{|l|c|c|c|}
\hline \multicolumn{1}{|c|}{ Setores } & Direta & Indireta & Induzida \\
\hline Soja & 14 & 170 & 267 \\
\hline Aves & 75 & 187 & 298 \\
\hline Bovinos & 70 & 137 & 291 \\
\hline Extrativismo vegetal & 48 & 82 & 312 \\
\hline Adubos e fertilizantes & 95 & 271 & 264 \\
\hline Beneficiamento de produtos vegetais & 60 & 172 & 293 \\
\hline Abate de outros animais & 46 & 238 & 280 \\
\hline Abate de bovinos & 26 & 193 & 277 \\
\hline Fabricação de óleos vegetais & 17 & 174 & 257 \\
\hline Comércio & 145 & 184 & 303 \\
\hline Instituições financeiras & 388 & 144 & 395 \\
\hline Serviços prestados às empresas & 383 & 115 & 390 \\
\hline Administração pública & 774 & 82 & 446 \\
\hline Serviços privados não mercantis & 926 & 17 & 471 \\
\hline
\end{tabular}

Fonte: Resultados da pesquisa.

Sabe-se que, de acordo com os clássicos Johnston e Mellor (1961), um dos papéis importantes a serem desempenhados pela agricultura no processo de crescimento econômico de um país é o de atrair ganhos cambiais com os quais os insumos críticos para o processo de desenvolvimento poderão ser adquiridos no exterior. A soja é o principal produto de exportação brasileira e o principal estado produtor e exportador, atualmente, é o Mato Grosso. 
Dessa forma, foram calculados os impactos das exportações de soja do estado, sobre a produção total e valor adicionado nos demais setores da economia.

A Tabela 5 mostra que, ao atender às exportações de soja do Mato Grosso (que na época da construção da matriz estavam em torno de R \$ 537 milhões ${ }^{3}$ ), diversos outros setores devem aumentar suas produções.

Dentro do próprio estado, os setores que mais tiveram impacto em suas produções foram os setores de Comércio, por ser o canal de comercialização, e o Transporte rodoviário, uma vez que praticamente toda a soja mato-grossense destinada à exportação é escoada para os portos via modal rodoviário (Ministério dos Transportes, 2004).

No restante do Brasil, o ramo mais impactado foi o setor de Adubos e fertilizantes, sugerindo que a maioria dos fertilizantes utilizados na produção agrícola do Mato Grosso é importada de outros estados brasileiros, evidenciando ainda mais a importância das relações comerciais entre as duas regiões.

Tabela 05. Produção (em mil Reais) gerada na economia ao atender as exportações de soja do Mato Grosso.

\begin{tabular}{clcc}
\hline $\mathrm{n}^{\circ}$ & \multicolumn{1}{c}{ Setores } & Mato Grosso & Restante do Brasil \\
\hline 2 & Soja & 688.541 & 15.275 \\
7 & Bovinos & 71.071 & 11.699 \\
10 & Extrativismo vegetal & 11.216 & 2.141 \\
13 & Extrativismo mineral & 5.443 & 64.441 \\
15 & Máquinas e Implementos agrícolas & 291 & 1.401 \\
16 & Outras máquinas e equipamentos & 336 & 23.566 \\
18 & Peças e veículos & 11 & 11.795 \\
23 & Refino do Petróleo & 25.428 & 281.515 \\
24 & Adubos e fertilizantes & 733 & 193.168 \\
33 & Fabricação de óleos vegetais & 515.802 & 12.724 \\
34 & Rações & 186 & 14.407 \\
37 & S.I.U.P & 34.756 & 31.631 \\
39 & Comércio & 275.005 & 64.866 \\
40 & Transporte rodoviário & 66.371 & 14.246 \\
42 & Transporte ferroviário & 11.767 & 10.366 \\
\hline
\end{tabular}

Fonte: Resultados da pesquisa.

${ }^{3}$ Banco de dados original encontra-se em Figueiredo (2003). 
Relação econômica dos setores agrícolas do Estado do Mato Grosso com os demais setores pertencentes tanto ao Estado quanto ao restante do Brasil

\section{Conclusão}

Os resultados empíricos confirmaram a relevância dos setores primários do Mato Grosso, em termos de suas relações comerciais com as demais atividades, destacando-se tanto como importantes compradores de bens e serviços quanto como importantes fornecedores de insumos para os demais setores, o que vem a contemplar dois dos principais papéis a serem desempenhados pela agricultura no processo de desenvolvimento econômico de um país, a saber: fornecimento de matéria-prima para o desenvolvimento do setor não-agrícola e constituir importante mercado consumidor para os produtos industrializados.

Os resultados permitiram identificar, ainda, um terceiro papel desempenhado pela agricultura no processo de desenvolvimento econômico, cumprido pelo setor agrícola do Mato Grosso, que é o de atrair ganhos cambiais ao Brasil por meio de suas exportações. Verificou-se que as vendas de soja do Mato Grosso a outros países, além de impactarem positivamente na produção de diversos outros setores pertencentes tanto ao próprio estado quanto ao restante do país, também atraíram ganhos cambiais, contribuindo para o desenvolvimento econômico.

No que diz respeito à capacidade de geração de emprego e renda na economia, observou-se que, de um modo geral, os setores primários e aqueles diretamente relacionados a eles, geram relativamente poucos empregos diretos e, conseqüentemente, renda direta na economia, em contrapartida a uma elevada capacidade de multiplicação do emprego e renda nas demais atividades fornecedoras de insumos à sua produção.

Isso sugere que, na medida em que os setores agrícolas vão se especializando e se intensificando em capital, necessitam de um número menor de pessoas trabalhando diretamente, porém, de uma quantidade maior de insumos, o que acaba demandando mais pessoas para atuar em outras atividades, de modo que aquele excedente de mão-de-obra que inicialmente trabalhava diretamente nestes setores acaba se deslocando para outras atividades. Desta forma, tem-se um quarto papel da agricultura no desenvolvimento econômico sendo desempenhado, que é o de fornecer mão-de-obra para o incremento dos setores não-agrícolas.

Com relação ao quinto papel a ser desempenhado pela agricultura no processo de desenvolvimento econômico, que é o de fornecer alimentos para 
a população, embora não seja objeto direto de estudo nesta pesquisa, está implícito o seu cumprimento pelos setores agrícolas do Mato Grosso, uma vez que, um estado com tamanha produção agropecuária, naturalmente seja fornecedor de alimentos para a população, não só do Mato Grosso, como também do restante do Brasil e de algumas outras partes do mundo.

Além de comprovar a importância dos setores primários na estrutura produtiva do Mato Grosso, cumprindo com todos os papéis a serem desempenhados pela agricultura no processo de desenvolvimento econômico, os resultados do trabalho dão conta da forte relação entre as economias do estado e do restante do país, e no que se refere ao setor primário, os resultados sugerem que há forte dependência de insumos importados das demais regiões brasileiras. Ademais, parte considerável da produção agropecuária é exportada do estado, tornando-se claro, portanto, que investimentos em infra-estrutura são de vital importância para a manutenção do crescimento econômico do Mato Grosso.

\section{Referências Bibliográficas}

BRASIL. Ministério do Desenvolvimento, Indústria e Comércio Exterior. Comércio exterior: indicadores e estatísticas: commodities. http://www. mdic.gov.br. (07 mar. 2003).

BRASIL. Ministério dos Transportes. http://www.transportes.gov.br. (12 jul. 2004).

CENTRO DE ESTUDOS AVANÇADOS EM ECONOMIA APLICADA (CEPEA). PIB do agronegócio. http://cepea.esalq.usp.br (20 abr. 2003)

COMPANHIA NACIONAL DO ABASTECIMENTO. Indicadores agropecuários. http://www.conab.gov.br. (27 fev. 2003)

CONFEDERAÇÃO NACIONAL DA AGRICULTURA E PECUÁRIA. Renda agropecuária. http://www.cna.org.br (20 abr. 2003)

CROCOMO, F.C. Análise das relações inter-regionais e intersetoriais na economia brasileira em 1985: uma aplicação de insumo-produto. Piracicaba, 1998. 179p. Tese (Doutorado) - Escola Superior de Agricultura “Luiz de Queiroz”, Universidade de São Paulo. 
EMPRESA BRASILEIRA DE PESQUISA AGROPECUÁRIA. Tecnologias de produção de soja na região central do Brasil. Londrina: Embrapa Soja, 2002. 199p.

FAO. Statistical databases: Faostat: agriculture. http://www.fao.org. (01 Mar. 2003).

FIGUEIREDO, M.G. Agricultura e estrutura produtiva do Estado do Mato Grosso: uma análise insumo-produto. Piracicaba, 2003. 205p. Dissertação (Mestrado) - Escola Superior de Agricultura "Luiz de Queiroz", Universidade de São Paulo.

GUILHOTO, J.J.M.; SONIS, M.; HEWINGS, G.J.D. Linkages and multipliers in a multiregional framework: integrations of alternative approaches. Illinois: REAL, 1996. 19p. (Discussion Paper, 8)

GUILHOTO, J.J.M.; HEWINGS, G.J.D.; SONIS, M. Productive relations in the northeast and the rest of Brazil regions in 1992 : decomposition \& synergy in input-output systems. In: ENCONTRO NACIONAL DE ECONOMIA, 27, Belém, 1999. v. 2. p. 1437-1450.

GUILHOTO, J.J.M.; SESSO FILHO, U.A.; LOPES, R.L.; HILGEMBERG, C.M.A.T.; HILGEMBERG, E.M. Nota metodológica: construção da matriz insumo-produto utilizando dados preliminares das contas nacionais (compact disc). In: ENCONTRO BRASILEIRO DE ESTUDOS REGIONAIS E URBANOS, 2., São Paulo, 2002. Anais. Belo Horizonte: Associação Brasileira de Estudos Regionais, 2002a.

GUILHOTO, J.J.M.; HEWINGS, G.J.D.; SONIS, M. Productive relations in the northeast and the rest-of-Brazil regions in 1995 : decomposition and synergy in input-output systems. Geographical Analysis, v. 34, n. 1, p. 62-75, jan., 2002b.

INSTITUTO BRASILEIRO DE GEOGRAFIA E ESTATÍsTICA. Contas nacionais: Brasil: 1999-2001. http://www.ibge.gov.br (02 out. 2003)

ISARD, Methods of interregional and regional analysis. Aldershot: Brookfield, 1998, 490 p.

JOHNSTON, B.F.; MELLOR, J.W. The role of agriculture in economic development. American Economic Review, v.51, n.4, p.566-593, Set. 1961. 
LEONTIEF, W. The structure of american economy, 1919-1939. New York: Oxford University Press, 1966. 264p.

MONTOYA, M.A. A matriz insumo-produto internacional do Mercosul em 1990 : a desigualdade regional e o impacto intersetorial do comércio inter-regional. Piracicaba, 1998. 217 p. Tese (Doutorado) - Escola Superior de Agricultura “Luiz de Queiroz”, Universidade de São Paulo.

MORETTO, A.C. Relações intersetoriais e inter-regionais na economia paranaense em 1995. Piracicaba, 2000. 160p. Tese (Doutorado) - Escola Superior de Agricultura “Luiz de Queiroz”, Universidade de São Paulo MOURA, J.G.; CÂMARA, S.F.; LIMA, R.C. Eficiência alocativa e crescimento econômico: o papel do setor agrícola (compact disc). In: CONGRESSO BRASILEIRO DE ECONOMIA E SOCIOLOGIA RURAL, 41., Foz do Iguaçu, 1999. Anais. Brasília: SOBER, 1999.

OLIVEIRA, N.M. Transporte e localização da agroindústria da soja no Estado de Mato Grosso. Viçosa, 2003. 138p. Dissertação (Mestrado) - Universidade Federal de Viçosa.

PARRÉ, J.L. O agronegócio nas macrorregiões brasileiras : 1985 a 1995. Piracicaba, 2000. 191p. Tese (Doutorado) - Escola Superior de Agricultura “Luiz de Queiroz”, Universidade de São Paulo

SILVA, C.E.L Como as economias de São Paulo e de Minas Gerais se comparam às do resto do Brasil : uma análise das suas estruturas produtivas. Piracicaba, 2001. 108p. Dissertação (Mestrado) - Escola Superior de Agricultura “Luiz de Queiroz”, Universidade de São Paulo.

SILVEIRA, S.F.R. Inter-relações econômicas dos Estados na Bacia do Rio São Francisco : uma análise de insumo - produto. Piracicaba, 2000. 245p. Tese (Doutorado) - Escola Superior de Agricultura “Luiz de Queiroz”, Universidade de São Paulo.

SOUSA, I.S.F. Condicionantes da modernização da soja no Brasil. Revista de Economia e Sociologia Rural, Brasília, v. 28, n. 2, p. 175-212, abr/jun. 1990.

Recebido em outubro de 2004 e revisto em junho de 2005 